\title{
Trends in Interactional Competence: Targeting Engagement and Explicit Utterances
}

\author{
Yumei Li \\ Foreign Language Publications, Higher Education Press, Beijing, China \\ Email: 16873516@qq.com
}

How to cite this paper: Li, Y. M. (2020). Trends in Interactional Competence: Targeting Engagement and Explicit Utterances. Creative Education, 11, 2617-2626. https://doi.org/10.4236/ce.2020.1112194

Received: November 5, 2020

Accepted: December 12, 2020

Published: December 15, 2020

Copyright $\odot 2020$ by author(s) and Scientific Research Publishing Inc. This work is licensed under the Creative Commons Attribution International License (CC BY 4.0).

http://creativecommons.org/licenses/by/4.0/

\section{(c) (i) Open Access}

\begin{abstract}
This paper aims to examine how an IELTS candidate keeps himself engaged in communication and conveys his ideas clearly to the examiner in the speaking section. Despite very occasional errors, the candidate shows fluency and a good mastery of vocabulary and grammatical knowledge. His performance demonstrates his abilities in interactional competence, a construct of speaking pedagogy that highlights dynamics of interaction between participants of a conversation. The nature of interactional competence requires the speaker to make utterance explicit to the listener and actively respond to the conversation partner. Influencing factors of interactional competence include speaking skills, communication abilities, cognitive skills and contextual factors. Issues might arise from unmanageable factors in some occasions, which requires the test taker to adapt to changes and adjust utterances as an engaged listener. Thus, contingent responses reflect comprehension and engagement in interactions. In this case, the speaker responds to the examiner by expanding information with a flexible use of vocabulary, grammatical structures and pronunciation skills. Examples show that major contributors to errors might be inattentiveness and lack of context awareness. If he fixes the problems in his speech, he can improve his rating on the marking rubric in future tests.
\end{abstract}

\section{Keywords}

Interactional Competence, Meaningful Output, Engagement, Explicit Utterances, Contingent Responses, Contextual Factors

\section{Introduction}

Many mountain hikers have an experience of making echoes roar in a valley-it seems like a conversation between you and yourself. This turn-taking process features a strong sense of engagement due to the interactional response generated within the process. The echo effect inspires test takers to proactively com- 
municate with partners in speaking proficiency tests, which helps them better achieve in paired speaking activities. They may report a sense of ease, a high level of self-efficacy and a deep engagement in communication. In some cases, IELTS test takers report a significant disparity on the speaking scores between different tests. The underlying reasons are complex due to a variety of influencing factors, among which engagement and competent responses are considered important factors that affect a test taker's performance. In other cases, some test takers complain that in computer-delivered speaking tests they tend to perform not as well as in face-to-face interview tests, which is largely due to lack of genuine response from a conversation partner. This means that it is essential to examine the effect of engagement and linguistic choices on the achievement of test takers, especially in what ways a speaker can achieve to make utterance explicit and unambiguous. Based on comments from the examiner, this paper attempts to explore the successful strategies that a particular speaker applies to achieve a 7.5 band score in an IELTS speaking test.

A rich body of literature shows that paired speaking tests are commonly used in classroom assessments and high-stakes language tests (May, 2011; Roever \& Kasper, 2018). This test format features interactions between co-participants. To enhance the effectiveness of interactions, a test taker needs to demonstrate communicative abilities and make appropriate linguistic choices. Literature shows that Interactional competence (IC) exerts a great influence on speaking performance. Galaczi and Taylor (2018) introduce that IC was first defined as a construct of "dynamic process of communication" (p. 220), giving prominence to the dynamics of conversation. Specifically, interaction not only entails negotiating intended meanings but also involves adjusting speech to serve a purpose. They further point out that IC was later redefined as a construct distributed across individual test takers that varies in different scenarios (Galaczi \& Taylor, 2018). This definition stresses the ability to engage in interaction in a meaningful and purposeful manner, highlighting the social and contextual dimensions. Roever and Kasper (2018) focus on contextual implications of IC for extended response of a polar question and for turn-taking skills to address misunderstandings. In addition, IC has implications for developing interactional skills, offering attractive user experiences and cutting-edge pedagogies (Galaczi \& Taylor, 2018). This study aims to provide a preliminary analysis into how an IELTS candidate constructs the responses and maintains the engagement. In the following section, the construct of IC will be introduced, followed by an analysis into linguistic evidence that could justify the effectiveness of IC from the aspects such as fluency and linguistic choices.

\section{Literature Review on Interactional Competence}

\subsection{The Conceptual Framework}

The focal constructs of IC include meaningful output, engagement and listener response (LR). Roever and Kasper (2018) point out that IC is a key construct in assessing language proficiency that highlights L2 users' ability to interact with 
the co-participant and to make meaningful output. Plough (2018) concludes that influencing factors of IC include listener responses, testing formats, tasks, rating scales and content knowledge. The study by Hall, Hellermann and Doehler (2011) emphasizes that IC refers to the ability to accomplish meaningful interactions, particularly on how the speaker responds to the co-participant and how to maintain a competent engagement in interactions.

May (2011) examines salient features of IC that are explicit to raters in a paired speaking test, elaborating interactional competences from a variety of perspectives such as turning taking, initiating topics and engaging in extended discourse. Based on the evidence of rater discussions and rater notes, the analysis indicates that mutual achievements have a significant impact on individual contributions (May, 2011). Similarly, Green (2016) emphasizes that although scores are awarded to individuals, talk is a product of interactions.

\subsection{A Sociolinguistic Perspective}

Hall et al. (2011) point out that competent interaction is based on socially constructed knowledge. Hence IC relates to sociocultural theory in terms of focused attention, cognitive functions, metacognition of intersubjectivity and other selfregulatory aspects (Hall et al., 2011; Cai, 2015). The shift of focus from linguistic features to sociolinguistic perspectives sheds light on enhancing L2 speakers' linguistic competence. Roever and Kasper (2018) discriminate between the psycholinguistic-individualist and sociolinguistic-interactional perspectives of IC, elaborating on how linguistic choices affect effectiveness of interaction with a keen focus on situational and social dimensions of language use. Notably, Douglas (2010) points out that authenticity relates to appropriate response through conveyed information. In a sense, an effective response helps maintain a deep engagement in communication. The engagement in turn can make communication smoother and more interactive. In language assessments, to some extent, an engaged speaker can make a relaxed delivery and feel like talking with an acquaintance. Thus, the effect of IC could be examined from the perspectives of situational and social dimensions.

\subsection{Historical Background}

Galaczi and Taylor (2018) point out that the role of IC in language assessment could be traced back to speaking pedagogy in the 1880s with a focus on fluency, phonetics and pronunciation in classroom settings. They argue that this focus formed a basis for L2 assessment in the early $20^{\text {th }}$ century. Further, they point out that the pedagogical changes over the past century fostered language learning of L2 speakers. The 1970s saw a significant change in the impact on interaction in L2 speaking assessment. The change is largely due to the contributions by Hymes (1974) on the relationship between performance and competence, Halliday (1975) on the Systemic Functional Linguistics (SFL) and van Dijk (1977) on context and discourse. Particularly, Hymes (1974) highlights speech situation, speech act, speech event and contextual factors. In addition, Plough (2018) in- 
troduces the advancement of speaking test formats from dictations to face-toface interviews, from telephone-delivered interviews to computer-based interviews, from semi-direct speaking tests to the cutting-edge fully automated testing. Galaczi and Taylor (2018) point out that due to technological innovations, there is scope to examine computer-mediated interactions and automated assessment systems. In addition, there is scope to explore interdisciplinarity in research such as computational linguistics, behavioral and linguistic studies, linguistic ethnography and cross-cultural studies.

\subsection{Challenges and Controversial Issues}

Galaczi and Taylor (2018) point out that construct-related issues involve: 1) whether it is sufficiently specific and comprehensive for pedagogical purposes; 2) fairness affected by the relationship between IC performance and rating scales or examiner training materials; and 3) mediation in terms of translating from one language to another during the processes of reception, interaction and production. Galaczi and Taylor (2018) point out that test reliability issues may arise from broadness and comprehensiveness of the construct particularly on multiple choices of variance. Specifically, language testers may encounter problems in assessing students in pairs or groups due to uncontrollable variables and unknown consequences. These unmanageable factors may have a negative effect on test validity in terms of interpreting scores. Given this Galaczi and Taylor (2018) conclude that improving task control and narrowing construct coverage could potentially reduce the risk of test reliability. In addition, when examining the relationship between test authenticity and performance, Galaczi and Taylor (2018) state that there is a difficulty in capturing interactional features in terms of unpredictability of co-constructed interactions in speaking tests. To address the dilemma, they argue that test developers could use scoring models and test design to optimize the effects of the interactional construct and to reduce the reliability concerns. Roever and Kasper (2018) state that one particular challenge of IC has to do with the examiner-induced issues, particularly disfluencies or misunderstandings by test takers, emphasizing that these issues are primarily associated with IC rather than language proficiency. Additionally, May (2011) states that fundamental challenges of IC involve task design, rating scales and decisionmaking on individual contributions of IC. Plough (2018) points out that IC overlaps with pragmatics with regard to meaningful and purposeful communication. Nevertheless, IC distinguishes from pragmatics in terms of building and maintaining relationships.

\subsection{Incorporating Interactional Competence into Language Assessments}

Plough (2018) points out that incorporating IC into speaking assessments allows for a better representation of the construct. She explains that listener responses are dependent upon the speaking task and upon the examiner frames. In particular, Plough (2018) stresses that listener responses are considered ratable fea- 
tures of IC and reflect language proficiency on judging accuracy, fluency and coherence. She examines the role of listener response in a commonly used assessment format Oral Proficiency Interviews (OPI), concluding that listener response is a stable and salient indicator of speaking proficiency. More specifically, listener response requires the task taker to comprehend the co-participant's contributions to respond effectively and productively in the turn-taking in a paired speaking task.

Responses are constructed based on contributions and interactions of both co-participants in a paired speaking test. From the test taker's point of view, there are a range of strategies that can make responses more productive: 1) paraphrasing or summarizing previous speakers' contributions to demonstrate understandings; 2) expressing agreement or disagreement with co-participants; and 3) expanding information based on previous speakers' contributions. Lam (2019) focuses keenly on the relationship between the production of listener responses and IC proficiency, particularly on the quality of response production, arguing that contingent responses can be more effective than formulaic backchannels ${ }^{1}$ in terms of reflecting comprehension and engaging in interactions.

\section{A Case Analysis on Building Interactional Capacities}

The case to be analysed is posted by IELTS Official, retrieved from the website of YouTube (IELTS Official, 2015). In this case, the candidate receives a 7.5 band score in speaking as he shows a high conversational involvement and interacts with the examiner actively. He expands the information when he gives the answer to each question, and occasionally he repairs his answer and hesitates to search for information. Test designers and test givers acknowledge that self-correction is natural and understandable in any conversation. Hence the comments on his performance suggest the candidate is highly proficient and his utterances show no obvious effort. It could be concluded that his performance of IC indicates a high level of fluency (see marking criteria in Appendix). The analysis on his performance highlights how he succeeded in demonstrating a competent interaction from a variety of perspectives. The specific strategies and the salient language features will shed light on language learning, training and testing practices in future. The analysis will fall into two parts. Discussion in each part will focus on a particular aspect that represents an indicator of IC performance.

\subsection{Building Engagement}

The candidate successfully maintains a deep engagement with the examiner throughout the test. His engagement in communication is strengthened by the fluency in speech delivery and active response to each question. Although he occasionally hesitates, repeats and corrects himself, he demonstrates competent speaking skills in this test by responding to each question with ease (see Table 1 for details). The repetition and hesitation are probably due to unfamiliarity of the topic. This is in line with the theoretical explanation of Plough (2018) that

${ }^{1}$ Backchannels construe the same meaning as listener responses. 
listener responses are dependent upon the examiner's frame. In addition, according to Hall et al. (2011), the candidate's performance is based upon socially constructed knowledge. This means that the frame of the candidate's social knowledge determines the degree of familiarity with the topic and in turn it affects fluency and engagement. In other words, the level of fluency is to some extent topic specific, especially for second language learners. This accounts for the occasional fluency disorder on certain topics. In addition, Fulcher (2010) argues that in speaking tests, support from proficient interlocutors help scaffold the speech of the examinee. In this case, the support from the trained and certificated examiner assists the candidate in building engagement and developing fluency.

\subsection{Making Utterance Explicit}

Fulcher (2010) stresses on the importance that contingent responses should be assessed qualitatively rather than quantitatively. In what sense can a speaker construct appropriate and competent responses in a test? In this example, the candidate's responses provide linguistic evidence for the effective strategies including lexical choices, grammatical use and pronunciation skills. The candidate makes utterances clear to the examiner with a flexible use of vocabulary, including markers, idioms and collocations, yet he makes a few inappropriate choices such as that's not just my cup of tea (see Table 2). This informal expression indicates to some degree a lack of contextual awareness of the speaker. The candidate should keep in mind that a formal test requires a formal speech style. With regard to grammatical use, the candidate mostly makes error-free sentences, which demonstrates a good mastery of grammatical knowledge. The grammatical errors only occur when the candidate is less attentive. Hence the candidate needs to keep alert and avoid use of illogical sentence structures. In addition, it is the diverse pronunciation features supplemented with an effective use of stress and intonation that make his utterances unambiguous to the examiner. To perfect his speech, he needs to avoid inadvertent omissions and poorly formed sounds such as bot for "both" and vent for "went".

Table 1. Building engagement capacities.

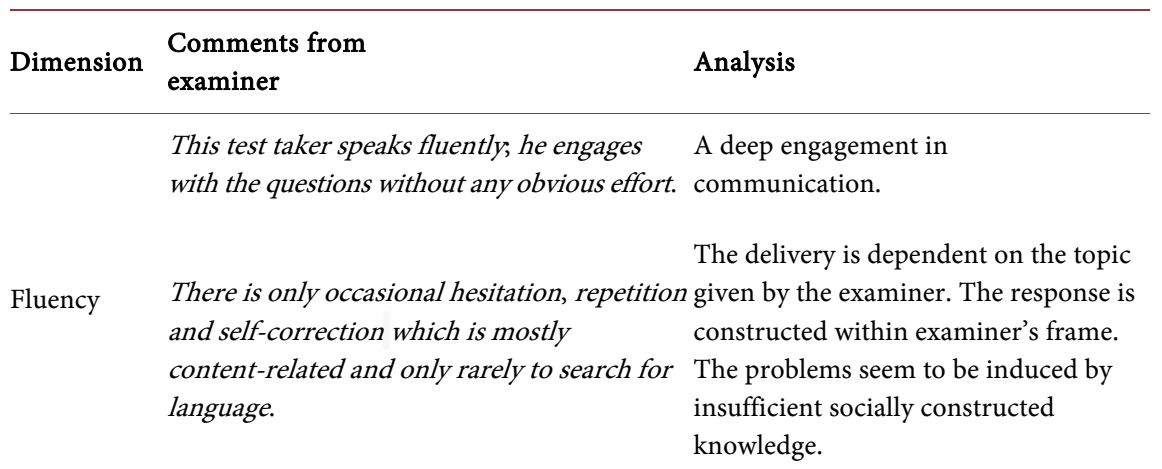

*Source: Comments from examiner are selected from posts by IELTS Official on YouTube via https://www.youtube.com/watch?v=cAf41I68HD8. 
Table 2. Making utterances explicit.

\begin{tabular}{|c|c|c|c|}
\hline Dimension & $\begin{array}{l}\text { Comments from } \\
\text { examiner }\end{array}$ & $\begin{array}{l}\text { The candidate's } \\
\text { utterances }\end{array}$ & Analysis \\
\hline \multirow[t]{2}{*}{ Lexical choice } & $\begin{array}{l}\text { His relaxed delivery is } \\
\text { supported by his flexible } \\
\text { use of markers. His } \\
\text { vocabulary is sufficient for } \\
\text { him to engage with a } \\
\text { variety of topics and he } \\
\text { demonstrates an ability to } \\
\text { use idioms and } \\
\text { collocations with some } \\
\text { sense of style and skill. }\end{array}$ & $\begin{array}{l}\text { (I am both; basically, as } \\
\text { well as; every now and } \\
\text { then; that would be } \\
\text { French) }\end{array}$ & $\begin{array}{l}\text { A competent vocabulary } \\
\text { acquisition and use; A } \\
\text { flexible use of markers, } \\
\text { idioms and collocations to } \\
\text { make the speech more } \\
\text { coherent }\end{array}$ \\
\hline & $\begin{array}{l}\text { he makes a number of } \\
\text { inappropriate vocabulary } \\
\text { choices, which restrict his } \\
\text { rating on this criterion. }\end{array}$ & $\begin{array}{l}\text { (all over the place; that's } \\
\text { not just my cup of tea; } \\
\text { someone to confront and } \\
\text { talk to; I haven't got a } \\
\text { chance) }\end{array}$ & $\begin{array}{l}\text { Lack of contextual } \\
\text { awareness; an inappropriate } \\
\text { use of informal expressions }\end{array}$ \\
\hline \multirow[t]{2}{*}{$\begin{array}{l}\text { Grammatical } \\
\text { use }\end{array}$} & $\begin{array}{l}\text { He has a wide range of } \\
\text { grammatical structures at } \\
\text { his disposal and the } \\
\text { majority of sentences are } \\
\text { error-free. }\end{array}$ & & $\begin{array}{l}\text { A good mastery of } \\
\text { grammatical knowledge }\end{array}$ \\
\hline & $\begin{array}{l}\text { Even when errors do very } \\
\text { occasionally occur, they do } \\
\text { not detract at all from } \\
\text { meaning. }\end{array}$ & $\begin{array}{l}\text { (I work part-time as well as } \\
\text { a student, it just does not } \\
\text { come into me) }\end{array}$ & $\begin{array}{l}\text { The errors occur only due } \\
\text { to lack of attention. }\end{array}$ \\
\hline \multirow[t]{2}{*}{ Pronunciation } & $\begin{array}{l}\text { He uses a wide range of } \\
\text { pronunciation features and } \\
\text { is able to use stress and } \\
\text { intonation effectively. }\end{array}$ & & $\begin{array}{l}\text { A good mastery of } \\
\text { pronunciation skills. }\end{array}$ \\
\hline & $\begin{array}{l}\text { There are just a few lapses } \\
\text { and very occasionally } \\
\text { sounds are poorly formed, } \\
\text { but overall, his accent has } \\
\text { only minimal effect on } \\
\text { intelligibility. }\end{array}$ & $\begin{array}{l}\text { (bot for "both"; vent for } \\
\text { "went") }\end{array}$ & $\begin{array}{l}\text { An inadvertent } \\
\text { omission. }\end{array}$ \\
\hline
\end{tabular}

* Source: Comments from examiner are selected from posts by IELTS Official on YouTube via https://www.youtube.com/watch?v=cAf41I68HD8.

\section{Implications}

Lin (2015) points out that IC has pedagogical implications for student motivation and self-efficacy in classroom learning. IC can facilitate students in adjusting learning behaviours and developing communication skills to make a better learning environment. It can also enhance knowledge accumulation, confidence building, and partnership establishment (Lin, 2015). IC also helps students enhance risk-taking ability and reduce speaking anxiety. Furthermore, Lin (2015) points out that IC facilitates self-diagnosis and self-regulation in terms of awareness of progress, performance level and individual contribution. Drawing on experiences from this case, learners can practise more to improve their performance on fluency, engagement, vocabulary, grammatical use as well as pronuncia- 
tion. For example, they can analyse a recorded speech of a paired speaking activity. They can ask for comments both from their partners and the instructor. Based on the comments, they can evaluate their strengths and weaknesses, and further perfect their speech in a simulated test.

Literature also shows that as a significant predicator of oral achievement, IC enables students to engage more in learning and to overcome psychological barriers (Lin, 2015). For example, reducing the level of anxiety can avoid underrepresentation of a test taker's speaking abilities such as fluency and vocabulary use. If a learner is well-prepared and makes a relaxed delivery in practice tests, it will be the same case with a real test. More importantly, test takers need to bear in mind that occasional illogical sentence structures and inappropriate vocabulary choices will not affect the overall performance. The examiner will judge upon the majority of utterances rather than minor errors as long as the errors do not detract from meaning.

IC assists students in developing cognitive skills such as critical thinking, logical thinking and holistic thinking. A speaker deeply engaged in the communication is likely to think logically, communicate smoothly, and organize the ideas coherently. When expanding information, the speaker needs to structure the sentences in a logical way. Meanwhile the speaker needs to stay alert for appropriateness all the way through the delivery. Considerations of appropriateness include contextual factors such as the examiner's follow-up questions, time control and other constraint factors.

From the test giver's perspective, exploring IC has implications for test and scale development in terms of designing appropriate and meaningful rating scales and rater training (Galaczi \& Taylor, 2018; May, 2011; Cai, 2015). For example, the case discussed above has been evaluated based on the examiner's comments in accordance to the IELTS marking rubric. Developing marking criteria for raters to use is important not only for ensuring the validity, reliability and fairness of the assessment but also for reducing disfluencies and misunderstandings by test takers. This will help scaffold the delivery of speech of the test takers. Given that the examiner in this case is expertly trained, the analysis shows that the candidate has received support from the examiner in developing a competent listener response.

\section{Conclusion}

The construct of IC relates to the speaking sub-skills such as fluency, pronunciation, grammatical range and lexical resources. The learners are required to make utterance explicit and respond to the co-participant effectively. Research to date shows that individual performance of IC is contingent on the context. In addition, there are a variety of factors such as examiner frames and contributions of co-participants that can affect the effect of IC. In high-stakes assessments examiner-induced responses of candidates are constrained within the examiner's frame, while in classroom contexts individual contributions in paired speaking 
practices are contingent on understandings of prompts or contributions of coparticipants. The analysis of this case suggests that language learners can improve their performance of IC through self-diagnosis and self-regulation in practice tests. They can identify their strengths and weaknesses in speaking with an evaluation of their former performance so that they can target on specific skills to perfect their speech. In particular, targeting engagement and utterances is key to the development of interactional capacities. From this perspective, we can conclude that effective speech delivery can be realized by enhancing engagement and improving the quality of utterances. Given that IC is significantly impacted by individual cognitive and contextual factors, it is essential that test designers attend to social dimensions of IC.

\section{Conflicts of Interest}

The author declares no conflicts of interest regarding the publication of this paper.

\section{References}

Cai, H. (2015). Weight-Based Classification of Raters and Rater Cognition in an EFL Speaking Test. Language Assessment Quarterly, 12(3), 262-282. https://doi.org/10.1080/15434303.2015.1053134

Douglas, D. (2010). Understanding Language Testing. London: Hodder Education.

Fulcher, G. (2010). Practical Language Testing. London: Hodder Education.

Galaczi, E., \& Taylor, L. (2018). Interactional Competence: Conceptualisations, Operationalisations, and Outstanding Questions. Language Assessment Quarterly, 15(3), 219 236. https://doi.org/10.1080/15434303.2018.1453816

Green, A. (2016). Exploring Language Assessment and Testing: Language in Action. Oxon: Routledge.

Hall, J. K., Hellermann, J., \& Doehler, S. P. (Eds.) (2011). L2 Interactional Competence and Development (Vol. 56). Blue Ridge Summit, PA: Multilingual Matters. https://doi.org/10.21832/9781847694072

Halliday, M. A. K. (1975). Learning How to Mean. In Foundations of Language Development (pp. 239-265). Academic Press. https://doi.org/10.1016/B978-0-12-443701-2.50025-1

Hymes, D. (1974). Ways of Speaking. Explorations in the Ethnography of Speaking, 1, 433451. https://doi.org/10.1017/CBO9780511611810.029

IELTS Official (2015). IELTS Speaking Test Sample-Part 1 (Aashish, Band 7.5). https://www.youtube.com/watch?v=cAf41168HD8

Lam, D. (2019). Interactional Competence with and without Extended Planning Time in a Group Oral Assessment. Language Assessment Quarterly, 16(1), 1-20. https://doi.org/10.1080/15434303.2019.1602627

Lin, L. (2015). Investigating Chinese HE EFL Classrooms: Using Collaborative Learning to Enhance Learning. Berlin: Springer.

May, L. (2011). Interactional Competence in a Paired Speaking Test: Features Salient to Raters. Language Assessment Quarterly, 8(2), 127-145. https://doi.org/10.1080/15434303.2011.565845 
Plough, I. (2018). Revisiting the Speaking Construct: The Question of Interactional Competence. Language Testing, 35(3), 325-329. https://doi.org/10.1177/0265532218772322

Roever, C., \& Kasper, G. (2018). Speaking in Turns and Sequences: Interactional Competence as a Target Construct in Testing Speaking. Language Testing, 35(3), 331-355. https://doi.org/10.1177/0265532218758128

Van Dijk, T. A. (1977). Text and Context: Explorations in the Semantics and Pragmatics of Discourse. London and New York: Longman.

\section{Appendix}

SPEAKING: Band Descriptors (public version)

\begin{tabular}{|c|c|c|c|c|}
\hline Band & Fluency and coherence & Lexical resource & Grammatical range and ace uracy & Pronunciation \\
\hline 9 & $\begin{array}{l}\text { - speaksfluently with only rare repetition or self-corredion; } \\
\text { - any hesitation is content-related rather than to find words } \\
\text { or grammar } \\
\text { - speaks coherently with fully appropriate cohesive features } \\
\text { - developstopics fully and appropriately }\end{array}$ & $\begin{array}{l}\text { - uses wocabulary with full flexibility and predsion in all } \\
\text { topics } \\
\text { - uses idiomatic language naturally and accurately }\end{array}$ & $\begin{array}{l}\text { - uses a full range of trudures naturally and appropriately } \\
\text { - produces consisently accurate structures apart from 'sips' } \\
\text { characteristic of native speaker speech }\end{array}$ & $\begin{array}{l}\text { - uses a full range of pronunciation feazture swith precision } \\
\text { and subtlety } \\
\text { - sustains llexible use of features throughout } \\
\text { - is effortless to understand }\end{array}$ \\
\hline 8 & $\begin{array}{l}\text { - speaksfluently with only occasional repettion or sell- } \\
\text { correction; hesitation is usually ontent-related and only } \\
\text { rarely to search for language } \\
\text { - developstopics coherently and appropriately }\end{array}$ & $\begin{array}{l}\text { - uses a wide vocabulary resource readily and flexibly to } \\
\text { onvey precise meaning } \\
\text { - uses less common and idiomatic vocabulary skiffully, with } \\
\text { occasional inaccuracies } \\
\text { - uses paraphrase effedively as required }\end{array}$ & $\begin{array}{l}\text { - uses a wide range of structuresflexibly } \\
\text { - producesa majority of error-free sentences with only very } \\
\text { occasional inappropriacies or basichon-systematic errors }\end{array}$ & $\begin{array}{l}\text { - uses a wide range of pronunciation features } \\
\text { - sutains flexible use of features, with only occasional } \\
\text { lapses } \\
\text { - is easy to understand throughout; } L 1 \text { accent has minimal } \\
\text { effed on intelligibility }\end{array}$ \\
\hline 7 & $\begin{array}{l}\text { - speaks at length without noticeable effort or loss of } \\
\text { coherence } \\
\text { - may demonstrate language-related hesitation at times, or } \\
\text { - some repettion andilor self-correction } \\
\text { sues a range of connectives and discourse markers with } \\
\text { some flexibility }\end{array}$ & $\begin{array}{l}\text { - uses wocabulary resource flevibly to discuss a variety of } \\
\text { topics } \\
\text { - uses some less common and idiomatic vocabulary and } \\
\text { shows some awareness of syle and collocation, with some } \\
\text { inappropriate choices } \\
\text { - uses paraphrase effedively }\end{array}$ & $\begin{array}{l}\text { - uses a range of complex structures with some flexibility } \\
\text { - frequently produces error-free sentences, though some } \\
\text { grammatical mista kes persist }\end{array}$ & $\begin{array}{l}\text { - shows all the positive features of Band } 6 \text { and some, but not } \\
\text { all, of the positive features of Band } 8\end{array}$ \\
\hline 6 & $\begin{array}{l}\text { - is willing to speak at length, though may lose coherence at } \\
\text { times due to occasional repettion, self--orredion or } \\
\text { hesitation } \\
\text { - uses a range of connectives and discourse markers but not } \\
\text { allways appropriately }\end{array}$ & $\begin{array}{l}\text { - hasa wide enough wocabularyto discuss topics at length } \\
\text { and make meaning dear in spite of inappropriacies } \\
\text { - generally paraphrases suocessfully }\end{array}$ & $\begin{array}{l}\text { - uses a mix of simple and complex structures, but with } \\
\text { limited flexibility } \\
\text { may make frequent ristakes with complex structures } \\
\text { though these rarely cause comprehension problems }\end{array}$ & $\begin{array}{l}\text { - uses a range of pronunciation features with mixed control } \\
\text { - shows some effective use of features but this is not } \\
\text { sustained } \\
\text { - can generally be undersood throughout, though } \\
\text { mispronunciation of individual words or sounds reduces } \\
\text { darity at times }\end{array}$ \\
\hline 5 & $\begin{array}{l}\text { - usually maintains flow of speech but uses repettion, self } \\
\text { correction and lor sow speech to keep going } \\
\text { - may overuse certain connectives and discourse markers } \\
\text { - produces simple speech fluently, but more œmplex } \\
\text { cormunication causes fluency problems }\end{array}$ & $\begin{array}{l}\text { - manages to talk about familiar and unfamiliar topics but } \\
\text { uses wocabulary with liminted flexibility } \\
\text { - attempts to use paraphrase but with mixed suocess }\end{array}$ & $\begin{array}{l}\text { - produces basic sentence forms with reasonable accuracy } \\
\text { - usesa lirited range of more complex srudures, but these } \\
\text { usually ontain errors and may cause some corrprehension } \\
\text { problems } \\
\text { - shows all the positive features of Band } 4 \text { and some, but not } \\
\text { all, of the positive features of Band } 6\end{array}$ & $\begin{array}{l}\text { - produces basic sentence forms with reasonable accuracy } \\
\text { - uses a limited range of more complex structures, but these } \\
\text { usually contain errors and may cause some comprehension } \\
\text { problems } \\
\text { - shows sllt the positive features of Band } 4 \text { and some, but not } \\
\text { all, of the positive features of Band } 6\end{array}$ \\
\hline 4 & $\begin{array}{l}\text { - cannot respond without noticeable pauses and may speak } \\
\text { slowly, with frequentrepettion and setf-correction } \\
\text { - links basic sentencos but with repettitious use of simple } \\
\text { connedives and some breakdown sin coherence }\end{array}$ & $\begin{array}{l}\text { - is able to talk about familiartopics but can only convey } \\
\text { basic meaning on unfarmiliar topics and makes frequent } \\
\text { - rerorsin word choice } \\
\text { - rarely attempts paraphrase }\end{array}$ & $\begin{array}{l}\text { - produces basic sentence forms and some corred simple } \\
\text { sentences but subordinate structures are rare } \\
\text { - errors are frequent and may lead to misunderstanding }\end{array}$ & $\begin{array}{l}\text { - uses a limited range of pronunciation features } \\
\text { - attempts to control features but lapses are frequent } \\
\text { for the listener }\end{array}$ \\
\hline 3 & $\begin{array}{l}\text { - speaks with long pauses } \\
\text { - has limited ability to link simple sentences } \\
\text { - gives only simple responses and is frequertly unable to } \\
\text { convey basic message }\end{array}$ & $\begin{array}{l}\text { - uses simple vocabularyto convey personal information } \\
\text { - has insufficient vocabulary for less fariliar topics }\end{array}$ & $\begin{array}{l}\text { - attempts basic sentence foms but with limited success, or } \\
\text { relies on apparently memonised utterances } \\
\text { - makes numerous errors except in memorised expressions }\end{array}$ & $\begin{array}{l}\text { - shows some of the features of Band } 2 \text { and some, but not } \\
\text { all, of the positive features of Band } 4\end{array}$ \\
\hline 2 & $\begin{array}{l}\text { - pauses lengthily before most words } \\
\text { - Itttle communication possible }\end{array}$ & - only produces isolated words or memorised utterances & - cannot produce basic sentenœe forms & - Speech is often unintelligble \\
\hline 1 & $\begin{array}{l}- \text { no commrunication possible } \\
\text { - no rateable language }\end{array}$ & & & \\
\hline 0 & - doesnot attend & & & \\
\hline
\end{tabular}

Source: IELTS official website, retrieved from https://ielts.com.au/wp-content/uploads/2018/10/Speaking-Band-descriptors.pdf. 